\title{
CONCEPTION CONTROL BY MONTHLY INJECTIONS OF MEDROXYPROGESTERONE SUSPENSION AND A LONG-ACTING OESTROGEN
}

\author{
ELSIMAR METZKER COUTINHO AND JOSE CARLOS DE SOUZA
}

\author{
The Departments of Obstetrics (Maternidade Climerio de Oliveira) \\ and Biochemistry, University of Bahia, Brazil
}

(Received 19th Fanuary 1967)

\begin{abstract}
Summary. An injectable mixture of $25 \mathrm{mg}$ of medroxyprogesterone with $5 \mathrm{mg}$ of oestradiol cypionate was administered monthly to a group of women of reproductive age for a period of 4 to 15 months. The treatment produced sterility in all patients. Minor changes in menstrual pattern were reported, but cyclic bleeding similar to menstruation was preserved in $85.1 \%$ of all cycles. Aside from the changes in menstrual pattern, no important side effects resulted from the treatment. Endometrial biopsies performed during the first months revealed distinct phases of endometrial proliferation and secretion, but after 6 months endometrial hypoplasia became the dominant feature. One indication that patients found the treatment acceptable was the low 'drop-out' rate (less than $5 \%$ at the end of 9 months). The treatment is proposed as an effective method of conception control.
\end{abstract}

\section{INTRODUCTION}

Several attempts have been made in the last 3 years to use long-acting progesterone derivatives as injectable contraceptives for women (Siegel, 1963; Felton, Hoelscher \& Swartz, 1965; Coutinho, de Souza \& Csapo, 1966; Rizkallah \& Taymor, 1966; Zanartu, Rice-Wray \& Goldzieher, 1966). Relatively successful clinical trials were carried out with: (1) hydroxyprogesterone caproate, (2) dihydroxyprogesterone acetophenide, and (3) $6 \alpha$-methyl-17 $\alpha$ hydroxyprogesterone acetate (medroxyprogesterone). These progestins have been used alone or combined with an oestrogen.

The compound medroxyprogesterone acetate was found to be particularly effective-a single injection of $50 \mathrm{mg}$ produced sterility for at least 1 month while a $400 \mathrm{mg}$ injection had a contraceptive effect for about 3 months (Coutinho et al., 1966). The long-lasting effect was not achieved, however, without various undesirable side effects which made practical use of the drug problematic. Amenorrhoea was frequent and the interval between the injection and the occurrence of bleeding was erratic and unpredictable. These side effects probably accounted for the high patient 'drop-out' rate which reached an average of $42 \%$ at the end of 9 months. Since these side effects were somewhat 
mitigated at the lower dose level, it was thought that greater predictability in cyclic bleeding and a lower incidence of side effects could be attained by further reducing the gestagen and applying it in association with an oestrogen. The present report describes the results of such a low dosage treatment in which a mixture of medroxyprogesterone acetate and a long-acting oestrogen was tested on a sample of women of reproductive age.

\section{PATIENTS AND METHODS}

The 104 patients accepted in the study group were women of proven fertility as indicated by at least one previous successful pregnancy. Eighty-three and one-half per cent reported two to ten pregnancies before the treatment. The patients were between 19 and 42 years old, $85.5 \%$ between 20 and 35 years of age. Menstrual behaviour before administration of the drug was carefully investigated, and note was taken of patient comments and complaints.

Medroxyprogesterone acetate $(25 \mathrm{mg})$ in aqueous suspension (Depo-Provera) and $5 \mathrm{mg}$ of oestradiol cypionate (Depo-Estradiol) were administered intramuscularly every 28 to 32 days for a period ranging from 4 to 15 months. Treatment was simplified by mixing the two components in the same syringe. Six hundred and twenty-three cycles out of a total of 634 were used for analysis of contraceptive effectiveness. Vaginal cytology was carried out in all patients at 6-month intervals. Endometrial biopsies were also performed on seventy-two patients before and during treatment.

\section{RESULTS}

No pregnancy occurred during the treatment, indicating $100 \%$ contraception effectiveness. The menstrual patterns are summarized in Text-fig. 1 where cycle length, duration and intensity of menstrual flow before and during treatment are compared. Changes occurred both in the duration and volume of menstrual flow. The amount of flow was considered to be normal in $74 \%$ of the cycles, whereas before treatment it was normal in $85 \%$ of the cycles. The number of cycles in which the patients bled for 2 to 5 days decreased from $74 \%$ to $55 \%$. However, in $85.1 \%$ of all the cycles the duration of flow was still from 2 to 8 days. Absence of bleeding occurred in only $5.9 \%$ (37) of the cycles. The bleeding pattern of one patient typical of $79 \%$ of the sample during 1 year of treatment is depicted in Text-fig. 2. The data show that bleeding occurred 15 to 20 days after the injection and lasted 3 to 8 days.

Endometrial biopsies performed in the first months of treatment revealed distinct phases of proliferation and secretion with varying degrees of hypoplasia. Hypoplasia became the dominating feature after 6 to 7 months of therapy. Plate 1 shows an endometrial biopsy made on the first phase of the second artificial cycle, i.e. 10 days after the first day of the last bleeding episode and another performed 12 days later on the same patient.

Aside from the changes described in the menstrual patterns, no important side effects were found. In fact, complaints of headache, nervousness, dizziness and nausea were less frequent during the treatment than before, as indicated 


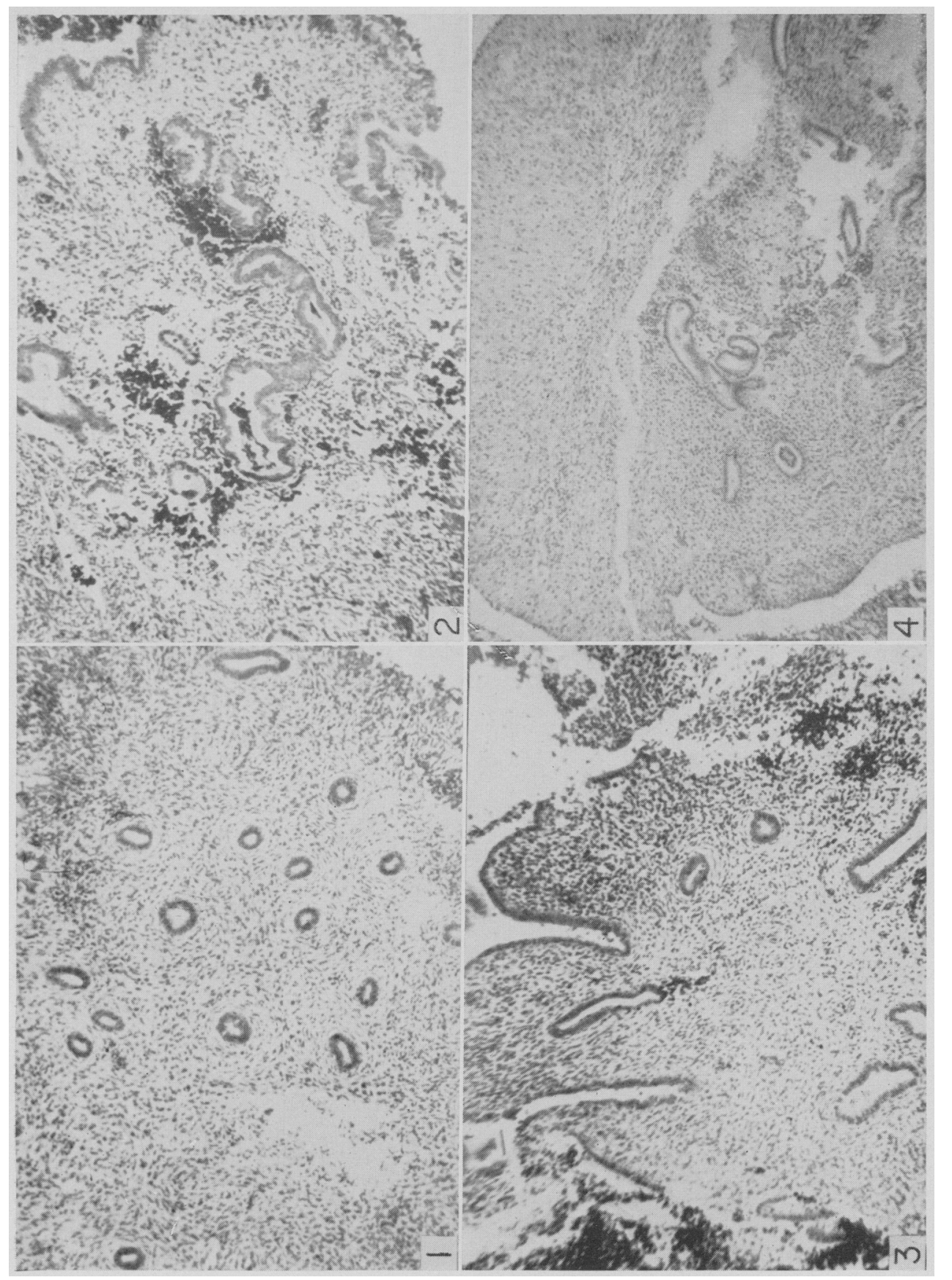

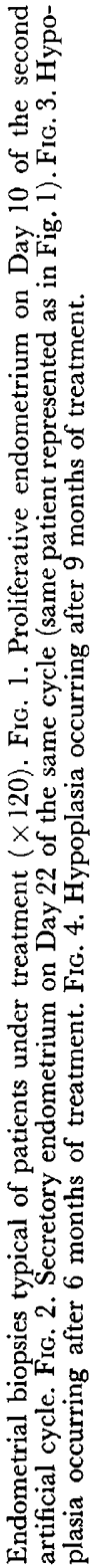

(Facing p. 210) 

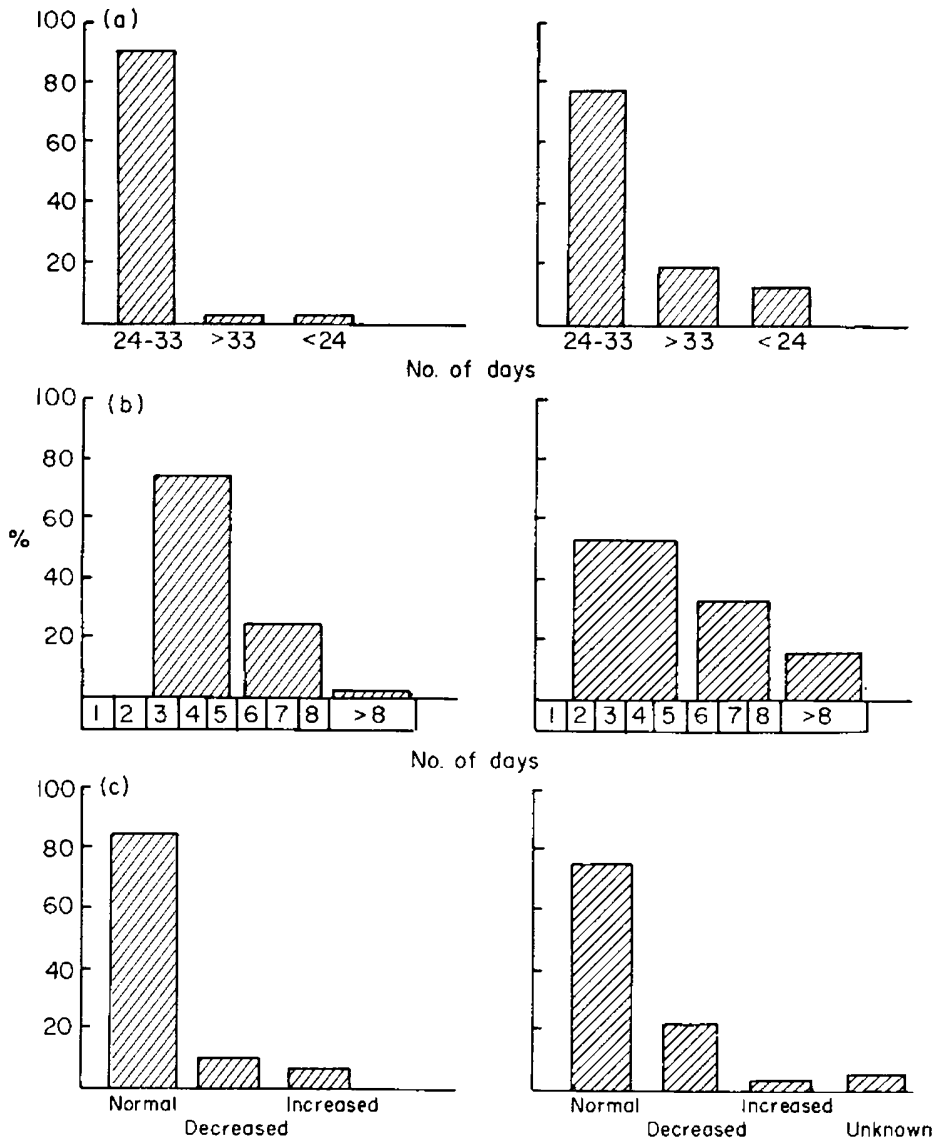

TEXT-FIG. 1. Comparison of: (a) cycle length, (b) duration of menstrual flow and (c) intensity of menstrual flow, before and during treatment.

CONCEPTION CONTROL

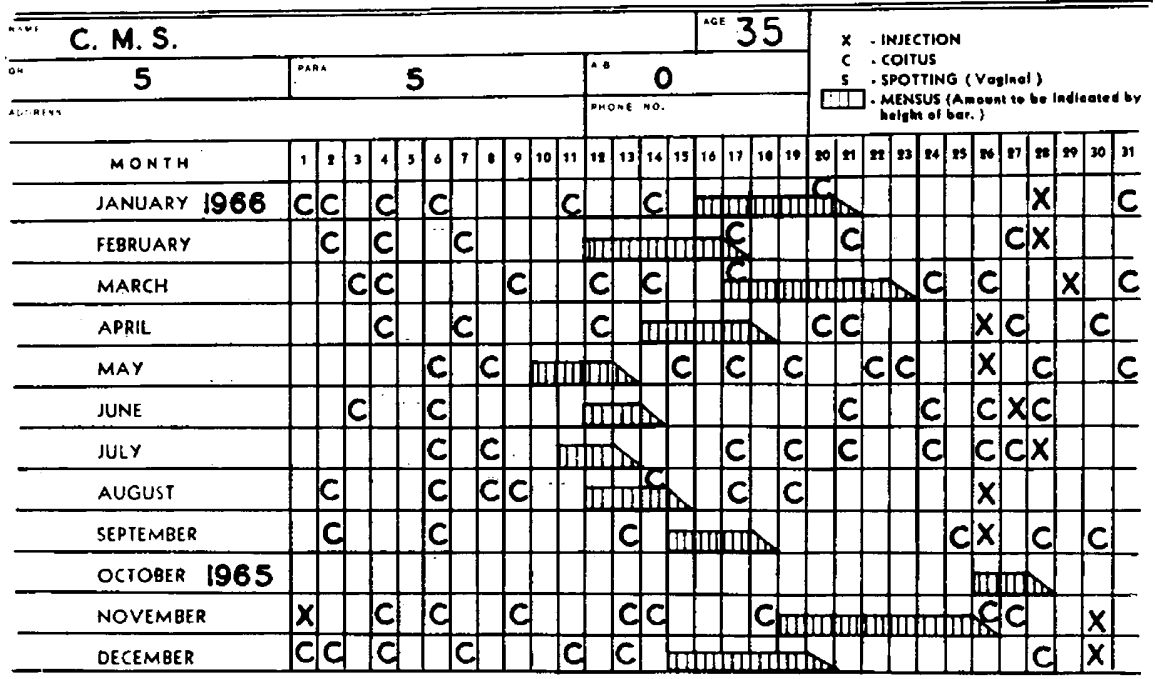

Texr-FIG. 2. Menstrual pattern of a patient over a period of 1 year. Note that the first injection was given on lst November 1965. 
in Table 1. It should be noted here that an objective evaluation of the mentioned side effects was difficult to obtain, and the above comparisons were necessarily derived from patients' statements. It is possible that the patients who claimed that nervousness, dizziness and cephalalgia were alleviated by the treatment

TABLE 1

INCIDENGE OF SIDE EFFECTS

\begin{tabular}{l|c|c}
\hline Side effect & Before treatment $(\%)$ & During treatment $(\%)$ \\
\cline { 2 - 3 } Headache & 53.8 & $14 \cdot 0$ \\
Nervousness & 49.0 & $7 \cdot 0$ \\
Dizziness & 44.2 & $15 \cdot 0$ \\
Nausea & 25.0 & $7 \cdot 0$ \\
\hline
\end{tabular}

might have done the same had they been given a placebo. Nevertheless, one important indication that the treatment caused no discomfort to the patients was the low rate of 'drop-out' (Text-fig. 3) which was less than $5 \%$ at the end of 9 months.

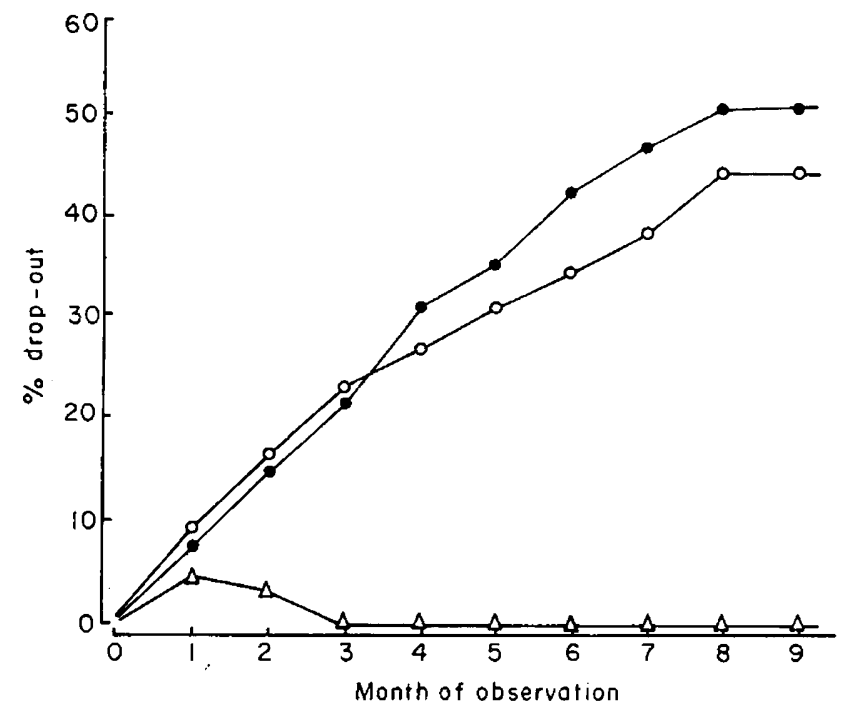

TEXT-FIG. 3. The data for the $50 \mathrm{mg}(0)$ and $100 \mathrm{mg}()_{)}$groups were taken from Coutinho et al. (1966). Note that 'drop-outs' in the 25-mg $(\Delta)$ group occurred only during the first 2 months of treatment.

About $50 \%$ of the patients gained weight during the treatment while only $15 \%$ lost weight. However, these changes in weight were not excessive (the maximum was $4 \mathrm{~kg}$ in I year) and did not seem to disturb the patients. There was no apparent change in breast morphology and function, and neither mastalgia nor breast discomfort was reported.

\section{DISGUSSION}

The following preliminary conclusions were derived from this study:

(1) The injection of a mixture of $25 \mathrm{mg}$ medroxyprogesterone and $5 \mathrm{mg}$ oestradiol cypionate has a contraceptive effect that lasts for at least 1 month. 
(2) Repeated injections of the mixture cause cyclic bleeding similar to menstruation in $79 \%$ of the patients.

(3) Except for the minor changes in menstrual pattern, the occurrence of side effects was found to be negligible.

(4) Distinct proliferative and secretory phases may be detected by endometrial biopsies performed up to the 4th month of treatment.

The latter finding indicates that cyclic ovarian function is preserved in the early stages of treatment. On the other hand, the fact that endometrial hypoplasia is consistently present during subsequent treatment suggests that suppression of ovarian function is progressive and possibly caused by a protracted or cumulative effect of the drug. This interpretation is in accord with the observations of Lemli, Aron \& Smith (1964) who administered Depo-Provera in doses of $50 \mathrm{mg}$ every 2 weeks for 2 to 5 months to girls with idiopathic isosexual precocity and found that the resulting decrease in biological oestrogen effect was not mediated through suppression of gonadotrophin production (Lemli et al., 1964). Whether this postulated cumulative effect occurs at the level of the ovaries (Lunenfeld, Sulimovici \& Raban, 1963), the adenohypophyses, the hypothalamus (Kistner, 1966; Rubin, 1964), or the uterus itself is still open to debate. However, if the effect is cumulative, as the results suggest, this would permit either increasing the interval between injections or decreasing the monthly dose of the gestagen after the 3rd or 4th month of treatment.

The use of a mixture of medroxyprogesterone acetate and oestradiol cypionate in monthly injections may provide an alternative to oral contraceptives when symptoms of gastric intolerance obviate the use of the 'pill'. It is also to be expected that a preference for an injected contraceptive will be found in certain populations where there is greater confidence in injections than in orally administered medicines. The belief that injections are more effective than other types of treatment is found in Brazil, the area of this study, and in many other Latin-American countries. It may be assumed that, where such a predisposition exists, injections will meet with greater receptivity than other contraceptive methods.

\section{ACKNOWLEDGMENTS}

Supported by the Ford Foundation. The authors are grateful to Dr Harold Upjohn and Dr Paul Schwallie from the Upjohn Company for supplying the drugs used in this study and for their valuable suggestions.

\section{REFERENCES}

Coutinho, E. M., De Souza, J. C. \& Csapo, A. I. (1966) Reversible sterility induced by medroxyprogesterone injections. Fert. Steril. 17, 261.

Felton, H. T., Hoelscher, E. W. \& Swartz, D. P. (1965) Evaluation of use of an injectable progestinestrogen for contraception. Fert. Steril. 16, 665.

KISTNER, R. W. (1966) Suppression of ovulation by pseudopregnancy treatment of endometriosis. In: Ovulation: Stimulation, Suppression, Detection, 1st edn, p. 254. Ed. Robert B. Greenblatt. J. B. Lippincott, Philadelphia and Toronto.

Lemli, L., Aron, M. \& Smrth, D. W. (1964) The action of Depo-Provera in 3 girls with idiopathic isosexual precocity: Decrease in estrogen effect without urinary gonadotropin reduction. 7. Pediat. 65, 888 . 
Lunenfeld, B., Sulmovici, S. \& Raban, E. (1963) Mechanism of action of anti-ovulatory compounds. 7. clin. Endocr. Metab. 23, 391.

Rizkallah, T. H. \& TAYMOR, M. L. (1966) Ovulation inhibition with a long-acting injectable. Am. F. Obstet. Gynec. 94, 161.

Rubiv, A. (1964) Prolonged amenorrhea following medroxyprogesterone. Am. F. Obstet. Gynec. 88, 1092.

SIEGEL, I. (1963) Conception control by long-acting progesterones: A preliminary report. Obstet. Gynec. 21,666 .

Zanartu, J., Rrce-Wray, E. \& Goldzieher, J. W. (1966) Fertility control with long-acting injectable steroids: A preliminary report. Obstet. Gynec. 28, 513. 